\title{
A humidity-controlled fast integrated mobility spectrometer (HFIMS) for rapid measurements of particle hygroscopic growth
}

\author{
Tamara Pinterich ${ }^{1}$, Steven R. Spielman ${ }^{2}$, Yang Wang ${ }^{1}$, Susanne V. Hering ${ }^{2}$, and Jian Wang ${ }^{1}$ \\ ${ }^{1}$ Brookhaven National Laboratory, Upton, NY 11973-5000, USA \\ ${ }^{2}$ Aerosol Dynamics Inc., Berkeley, CA 94710, USA \\ Correspondence: Jian Wang (jian@bnl.gov)
}

Received: 9 June 2017 - Discussion started: 26 June 2017

Revised: 19 October 2017 - Accepted: 30 October 2017 - Published: 15 December 2017

\begin{abstract}
We present a humidity-controlled fast integrated mobility spectrometer (HFIMS) for rapid particle hygroscopicity measurements. The HFIMS consists of a differential mobility analyzer (DMA), a relative humidity (RH) control unit and a water-based FIMS (WFIMS) coupled in series. The WFIMS (Pinterich et al., 2017) combines the fast integrated mobility spectrometer (Kulkarni and Wang, 2006a, b) with laminar flow water condensation methodologies (Hering and Stolzenburg, 2005; Spielman et al., 2017). Inside the WFIMS, particles of different electrical mobilities are spatially separated in an electric field, condensationally enlarged and imaged to provide $1 \mathrm{~Hz}$ measurements of size distribution spanning a factor of $\sim 3$ in particle diameter, which is sufficient to cover the entire range of growth factor (GF) for atmospheric aerosol particles at $90 \% \mathrm{RH}$. By replacing the second DMA of a traditional hygroscopicity tandem DMA (HTDMA) system with the WFIMS, the HFIMS greatly increases the speed of particle growth factor measurement.

The performance of the HFIMS was evaluated using $\mathrm{NaCl}$ particles with well-known hygroscopic growth behavior and further through measurements of ambient aerosols. Results show that the HFIMS can reproduce, within $2 \%$, the literature values for hygroscopic growth of $\mathrm{NaCl}$ particles. $\mathrm{NaCl}$ deliquescence was observed between 76 and $77 \% \mathrm{RH}$ in agreement with the theoretical value of $76.5 \%$ (Ming and Russell, 2001), and efflorescence relative humidity (43\%) was found to lie within the RH range of 41 to $56 \%$ reported in the literature. Ambient data indicate that the HFIMS can measure the hygroscopic growth of five standard dry particle sizes ranging from 35 to $165 \mathrm{~nm}$ within less than $3 \mathrm{~min}$, which makes it about 1 order of magnitude faster than traditional HTDMA systems.
\end{abstract}

\section{Introduction}

The hygroscopicity of atmospheric aerosols is a key parameter in determining their impact on global climate. The uptake of water by individual particles increases the light scattering, enhances heterogeneous chemical transformations important to secondary aerosol formation (e.g., Surratt et al., 2010) and is important in the formation of cloud droplets. The abundance of hygroscopic particles that act as cloud condensation nuclei affects cloud formation and cloud droplet number concentrations, which in turn influences cloud albedo, coverage and lifetime (Twomey, 1977; Albrecht, 1989). These "indirect effects" of atmospheric aerosols on the Earth's radiation balance remain one of the largest uncertainties in understanding climate change (IPCC, 2013). Hygroscopicity is among the key determinants of the ability of aerosol particles to form cloud droplets and therefore the aerosol indirect effects (e.g., Mei et al., 2013; Liu and Wang, 2010).

Most commonly particle hygroscopic growth is measured using hygroscopicity tandem differential mobility analyzer (HTDMA) systems, which consist of two differential mobility analyzers (DMAs) in series, separated by a means to control the sample flow relative humidity (RH). HTDMA systems first select a single particle size using the first DMA, change its relative humidity environment, and then scan the classifying voltage of the second DMA to measure the distribution of particle sizes resulted from the change in RH. The HTDMA method is accurate, but slow. Typically the time required to complete a measurement cycle for determining the growth factor (GF) at a single relative humidity (such as $90 \%$ ) for 5 different particle sizes is about $30 \mathrm{~min}$ (e.g., Cerully et al., 2011). Measurement periods are espe- 
cially long for large particles which are low in concentration and for small particles that have a low charging efficiency.

Several investigators have worked to increase the speed of HTDMA measurements by replacing the second DMA with an instrument that is capable of fast size distribution measurements. Sorooshian et al. (2008) developed a differential aerosol sizing and hygroscopicity spectrometer probe (DASH-SP), in which wet particle size is measured by an optical particle counter (OPC). By replacing the second DMA with an optical counter, DASH-SP accelerates the measurement significantly. However, the optical counting limits DASH-SP measurements to particles larger than $\sim 150 \mathrm{~nm}$ in diameter, and a sophisticated algorithm is required to account for the variation of particle refractive index due to water uptake and its impact on optical sizing. Stolzenburg et al. (1998) developed a high-flow mobility analyzer which they coupled to an optical particle counter, with humidity control upstream of the mobility size separation and an aerosol dryer downstream to measure particle size change upon dehumidification. Leinert and Wiedensohler (2008) developed a DMA-aerodynamic particle sizing (APS) system to examine growth factors, but their measurements were complicated by the change in particle density, which affects the aerodynamic measurement. While faster, the limitation of these coupled DMA-optical counter or DMA-aerodynamic sizing technique systems is the limitation on the measurement size range and the additional complexity or uncertainty in mapping the optical or aerodynamic size onto the physical size of the particle that is important to assessing water uptake. These systems, based on optical sizing or aerodynamic sizing, are capable of measuring the hygroscopicity of large accumulation mode particles, which are important to evaluating the optical properties and direct radiative effects of ambient aerosols.

To address the need for fast and precise measurements of particle hygroscopic growth, we have developed a humiditycontrolled water-based fast integrated mobility spectrometer (HFIMS), which replaces the second DMA of the HTDMA systems with a water-based FIMS (WFIMS; Pinterich et al., 2017). By detecting particles of different sizes simultaneously, the WFIMS provides rapid measurements of the size distribution of humidified particles. Unlike the final optical sizing of Sorooshian et al. (2008) or the final aerodynamic sizing of Leinert and Wiedensohler (2008), the WFIMS measures particle sizes based on electrical mobility. This removes the uncertainty introduced by the particle refractive index or density and provides the same, precise growth factor measurements of the HTDMA systems, but with a much faster measurement speed. Compared to systems based on optical or aerodynamic sizing, the HFIMS extends fast measurements to particles with diameters below $150 \mathrm{~nm}$. Particles smaller than $150 \mathrm{~nm}$ often represent a large fraction of the cloud condensation nuclei population and may have a strong impact on human health (Chen et al., 2016). Using both laboratory and ambient measurements, we demonstrated that the
HFIMS can provide growth factor measurements with $1 \%$ precision for five representative particle diameters in less than $3 \mathrm{~min}$ - about 1 order of magnitude faster than traditional HTDMA systems.

\section{Instrument design}

The HFIMS consists of three individual units (see Fig. 1): a TSI Inc. DMA (either long-column or nano-column DMA, depending on the particle size) classifying particles at a desired dry size under a low RH, an RH control unit providing independent controls of the size-selected particle sample and WFIMS sheath flow RH, and a WFIMS measuring size distributions of particles after being exposed to a different RH. The WFIMS used here is identical to the original WFIMS (Pinterich et al., 2017), except the high-voltage (HV) electrode is replaced with one that provides a uniform electrical field with a small offset from the aerosol inlet slit, as described below. This modification is made to optimize the measurements of humidified particle size distributions. In essence, the WFIMS deployed in this study is similar to the alcohol-based FIMS reported in Kulkarni and Wang (2006a), except that particle growth is achieved by condensation of water instead of butanol, which is key to hygroscopicity measurements.

\subsection{Relative humidity control (RH control)}

An automated RH control system was constructed to independently control the RH of the size-selected aerosol sample flow $\left(\mathrm{RH}_{\mathrm{a}}\right)$ and the WFIMS sheath flow $\left(\mathrm{RH}_{\mathrm{sh}}\right)$. Humid air $(>95 \% \mathrm{RH})$ is created by bubbling dry air through sintered metal mufflers submerged in about $20 \mathrm{~cm}$ of water. The humid air is then mixed with dry air to provide the WFIMS sheath flow. The RH of the sheath flow is controlled by a proportional-integral-derivative (PID) controller that drives a proportional solenoid valve on the dry air line based on the sheath flow RH probe reading. The aerosol sample flow RH is controlled using a Nafion ${ }^{\circledR}$ exchanger, and the dry-humid mixture used as the purge flow of this exchanger is controlled independently. As with the sheath flow, the purge flow is obtained by the mixing of dry air with that from the humid air source, with a second PID controller that reads the aerosol RH and drives the valve on the dry air line to meet the target aerosol sample RH. To compensate for the evaporative cooling, the bubbler is equipped with a heater and a simple thermostat set to the room temperature (not shown in Fig. 1).

\subsection{Configuration of the WFIMS}

The WFIMS is identical to the original version presented in Pinterich et al. (2017) except that the HV electrode is replaced with one that provides a uniform electric field with a slight offset from the aerosol inlet slit. The WFIMS consists 


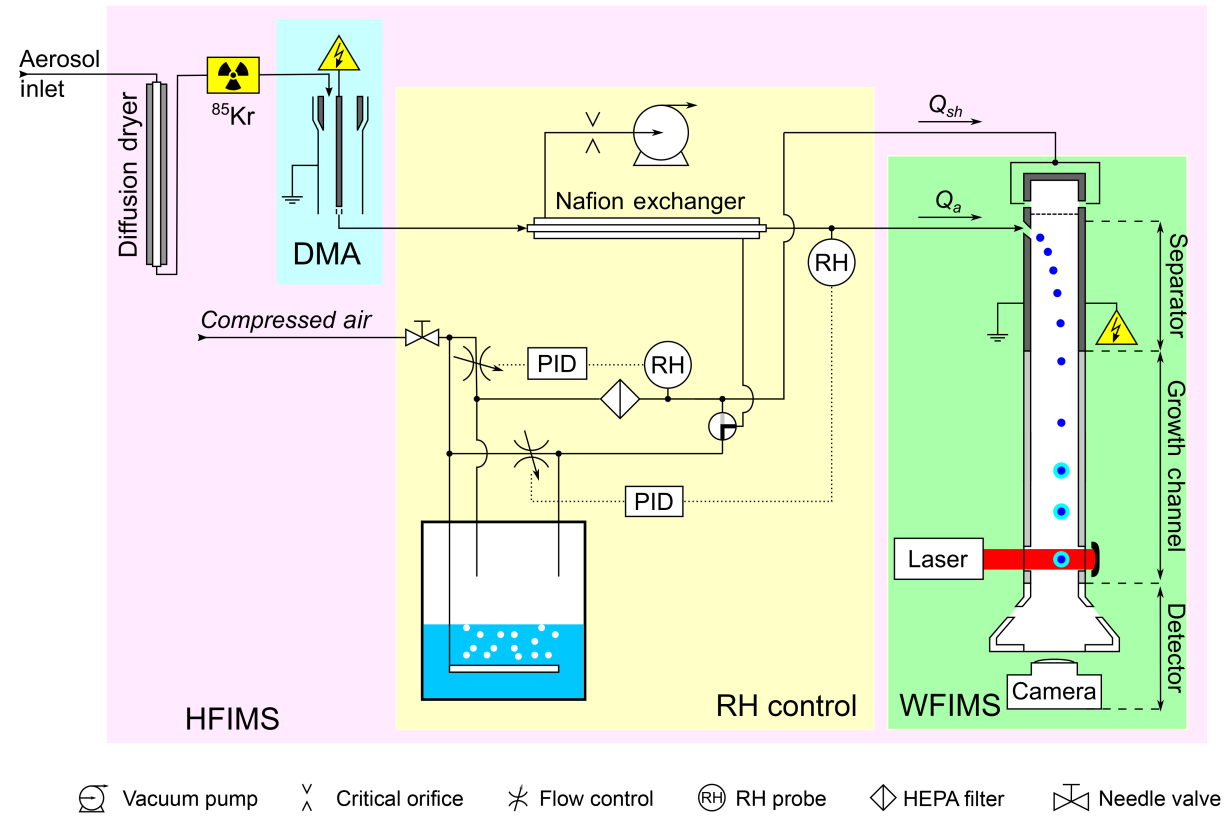

Figure 1. Schematic diagram of the HFIMS.

of a parallel plate mobility separator followed by a threestage condensational growth channel and an imaging system. A particle-free sheath flow $Q_{\text {sh }}$ enters at the top, and an aerosol flow $Q_{\mathrm{a}}$ is introduced through a slit along the entire width of the separator channel. A constant total flow $Q_{\text {tot }}$ of $16.5 \mathrm{~L} \mathrm{~min}^{-1}$ through the channel is achieved by a vacuum pump along with a critical orifice (O'Keefe Controls Co., no. 55). The desired $Q_{\mathrm{a}}$ of $0.3 \mathrm{Lmin}^{-1}$ is achieved via PID control of $Q_{\text {sh }}$ using a flow control valve (MKS Instruments, 0248A). The key physical dimensions and operating conditions of the WFIMS in this study are listed in the Supplement Sect. S1.

The WFIMS is configured with a single-voltage electrode that has an offset in the direction of the flow ( $z$ direction). A side view $((x, z)$ plane) of the WFIMS separator is shown in Fig. 2, where the flow is downward and the high-voltage electrode on the right is extending in $y$ direction. For measurements of particle growth factor, i.e., the ratio of humidified to dry particle diameter $D_{\mathrm{p}} / D_{\mathrm{p}, 0}$, the size range of the WFIMS only needs to cover the possible change in particle diameter. For ambient particles, the growth factor reported in the literature ranges from 0.8 to 2.2 for $\mathrm{RH}$ values up to $90 \%$. This range covers the GF of sea-salt-like particles (Ming and Russell, 2001) and also encompasses the $15 \%$ shrinkage observed for highly agglomerated particles that occurs when the branched structure collapses following the capillary condensation of water (Weingartner et al., 1995). Conveniently, the WFIMS operated with a single-voltage electrode has an electrical mobility range of a factor of 10 (Kulkarni and Wang, 2006a, b), which corresponds to more than a factor of 3 in

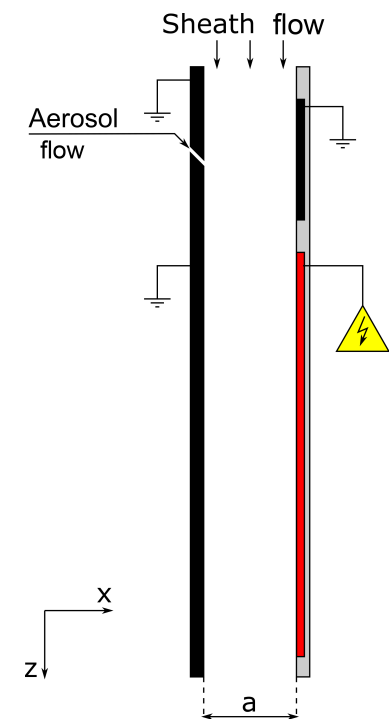

Figure 2. Schematic diagram of the offset electrode used in the HFIMS with the aerosol inlet on the left.

particle diameter, which is sufficient to cover the GF range of atmospheric aerosols.

The single high-voltage electrode was configured with an offset such that the high-voltage region (red area in Fig. 2) begins slightly downstream $(32 \mathrm{~mm})$ of the introduction of aerosol into the separator. The offset allows the sheath flow to provide the additional $\mathrm{RH}$ conditioning of the size-selected sample flow prior to mobility classification as the aerosol flow is less than $2 \%$ of the total flow. As the control of $\mathrm{RH}_{\mathrm{a}}$ 
is achieved by using a Nafion exchanger and has a longer response time than that of the WFIMS sheath flow, this feature could accelerate the growth factor measurements under different $\mathrm{RH}$ by reducing the waiting time following the change in the RH set points. However, in the present study we mainly focus on measurements at a single $\mathrm{RH}(85 \%)$ where this feature is not relevant.

A heater and thermistor were attached near the bottom of the separator to compensate for the heat loss to the adjacent cooled conditioner stage (see details in the next paragraph) and to avoid a corresponding change in $\mathrm{RH}$ due to this gradient. The heater was driven to equalize the temperatures within the separator. Without heating, the temperature at the bottom of the separator is about $1.0^{\circ} \mathrm{C}$ below that at the top.

Upon exiting the separator the particles continue along their flow trajectories through the three-stage growth channel, consisting of the conditioner, initiator and moderator, all with wetted walls (Spielman et al., 2017). Particles are enlarged through water condensation without being diverted from their trajectories. The WFIMS' three-stage growth channel design provides supersaturation levels of $\sim 1.35$ across its viewing window, which is sufficient to activate and grow particles as small as $7 \mathrm{~nm}$ to detectable sizes (Pinterich et al., 2017), while also removing excess water vapor that might otherwise condense on the optical components (Hering et al., 2014). Within the final section, grown particles are illuminated by a laser beam and imaged by a camera at a frame rate of $10 \mathrm{~Hz}$. MATLAB's "Image Processing Toolbox" is used to detect each droplet and its position. Only particles detected in the center of the channel cross section $((x, y)$ plane $)$ are used for measurements of particle size and concentration in order to avoid the edge effects of electric and flow fields (Olfert et al., 2008). For the WFIMS operated with a single-voltage electrode, particle positions can be converted to instrument response mobilities $Z_{\mathrm{p}}^{*}$, using Eq. (22) from Kulkarni and Wang (2006a):

$Z_{\mathrm{p}}^{*}=\frac{2(1+\beta)\left(3 \widetilde{x}^{2}-2 \widetilde{x}^{3}\right)-\beta}{2+\beta} \cdot Z_{\mathrm{p}, \max }^{*}$,

with flow ratio $\beta=Q_{\mathrm{a}} / Q_{\mathrm{sh}}$ and $\tilde{x}$ being the ratio of the $x$ coordinate of the detected particle to separator gap width $a$. Note that the conversion of particle position into instrument response mobility is independent of the applied particle enlargement technique (alcohol vs. water). The maximum response mobility $Z_{\mathrm{p}, \max }^{*}(\tilde{x}=1)$ measured by the (W)FIMS can be expressed as (Kulkarni and Wang, 2006a)

$Z_{\mathrm{p}, \max }^{*}=\frac{a \cdot Q_{\mathrm{a}}}{\beta\left(b \cdot l_{\mathrm{s}} \cdot V\right)}$,

with $b$ and $l_{\mathrm{s}}$ being the electrode width and length, respectively. $V$ is the voltage applied across the high-voltage electrode. Knowing $Z_{\mathrm{p} \text {, max }}^{*}$, the mobility resolution $R$, which is defined as the ratio of particle mobility $Z_{\mathrm{p}}$ to the full width at half height of the WFIMS transfer function $\Delta Z_{\mathrm{p}}^{*}$, can be calculated according to (Kulkarni and Wang, 2006a)

$R=\frac{Z_{\mathrm{p}}}{\Delta Z_{\mathrm{p}}^{*}} \cong \frac{Z_{\mathrm{p}}}{\beta \cdot Z_{\mathrm{p}, \max }^{*}}$.

Similar to a DMA, the mobility resolution of the (W)FIMS depends on the ratio of the sheath to aerosol flow. In addition, the (W)FIMS resolution is also a function of particle mobility $Z_{\mathrm{p}}$. In DMA classifiers all selected particles traverse the entire mobility separation channel. In contrast, in (W)FIMS systems, only the most mobile particles traverse the entire channel, while the less mobile particles traverse just a portion of the sheath flow. Thus, in the (W)FIMS, the mobility resolution reaches the maximum value of $1 / \beta$ only for the largest mobility measured (i.e., $Z_{\mathrm{p} \text {, max }}^{*}$ ), while the resolution for less mobile particles is lower. When operated at a fixed sheath flow of $16.2 \mathrm{~L} \mathrm{~min}^{-1}$ and an aerosol flow of $0.3 \mathrm{~L} \mathrm{~min}^{-1}$, as is our standard operating configuration, the resolution for those particles that traverse the entire channel is 54 , while that for particles traversing just one-half of the channel will be 27 .

In this study, the WFIMS separating voltages ranged from 70 to $4500 \mathrm{~V}$, allowing hygroscopicity measurements for particles with dry diameters ranging from 15 to $205 \mathrm{~nm}$. This includes the standard sizes from 35 to $165 \mathrm{~nm}$ suggested by the EUSAAR (European Supersites for Atmospheric Aerosol Research) project (Duplissy et al., 2009). Dry particle size ranges of the HFIMS and other representative instruments are shown in Table 1. Compared to the HFIMS, systems based on optical or aerodynamic sizing have a larger upper size limit. On the other hand, the HFIMS is capable of rapid measurement of particles with dry diameters below $150 \mathrm{~nm}$, which are difficult to detect using OPC or APS.

\section{Experimental setup}

The capability of the HFIMS to accurately characterize particle hygroscopicity is examined by measuring sodium chloride particles, for which hygroscopic growth has been well characterized in prior studies. The experimental setup is shown in Fig. 3. $\mathrm{NaCl}$ particles were generated by atomizing a dilute $\mathrm{NaCl}$ solution $(1.7 \mathrm{mM})$ using a constant output atomizer (TSI Inc., model 3076), followed by a diffusion dryer. A stable particle number concentration of about $50 \mathrm{~cm}^{-3}$ was achieved by adapting (i) the diameter of a limiting orifice in dilution stage 1 and (ii) the dry, particle-free dilution flow via a needle valve (dilution stage 2). After dilution, polydisperse particles were charge equilibrated using a ${ }^{85} \mathrm{Kr}$ bipolar aerosol neutralizer (TSI Inc., model 3077) and size selected at low humidity $(\mathrm{RH}<10 \%)$ using a nanocolumn DMA (TSI Inc., model 3085). In the present study we selected $50 \mathrm{~nm}$ particles. The ratio of the DMA aerosol to sheath and sample to excess flow was kept constant at $1: 10$. During laboratory characterization a condensation particle counter (CPC; TSI Inc., model 3010) was operated down- 
Table 1. Dry particle diameter range $\left(D_{\mathrm{p}, 0}^{\min }-D_{\mathrm{p}, 0}^{\max }\right)$ of four particle hygroscopicity instruments including the HFIMS. Diameter ranges of the HFIMS, Brechtel Mfg. (BMI), HTDMA and DASH-SP were estimated based on growth factors ranging from 0.8 to 2.2. The DASH-SP dry size range was estimated for a $5 \mathrm{~L} \mathrm{~min}^{-1} \mathrm{DMA}$ sheath flow rate, $281 \mathrm{~V}$ minimum classifying voltage and $135 \mathrm{~nm}$ cut size of the OPC as specified in Sorooshian et al. (2008). The particle dry diameter range of BMI HTDMA was calculated for a typical fieldwork configuration (i.e., $Q_{\mathrm{a}}=0.6 \mathrm{~L} \mathrm{~min}^{-1}, Q_{\mathrm{sh}}=6 \mathrm{~L} \mathrm{~min}^{-1}$, Lopez-Yglesias et al., 2014) and classifying and scanning voltages ranging from 20 to $6000 \mathrm{~V}$. The diameter range of the hygroscopicity-differential mobility analyzer-aerodynamic particle sizer (H-DMA-APS) is listed as specified in Leinert and Wiedensohler (2008).

\begin{tabular}{lrr}
\hline Instrument & $D_{\mathrm{p}, 0}^{\min }[\mathrm{nm}]$ & $D_{\mathrm{p}, 0}^{\max }[\mathrm{nm}]$ \\
\hline HFIMS (This study) & 15 & 205 \\
BMI HTDMA (Lopez-Yglesias et al., 2014) & 33 & 425 \\
DASH-SP (Sorooshian et al., 2008) & 170 & 455 \\
H-DMA-APS (Leinert and Wiedensohler, 2008) & 800 & 1600 \\
\hline
\end{tabular}

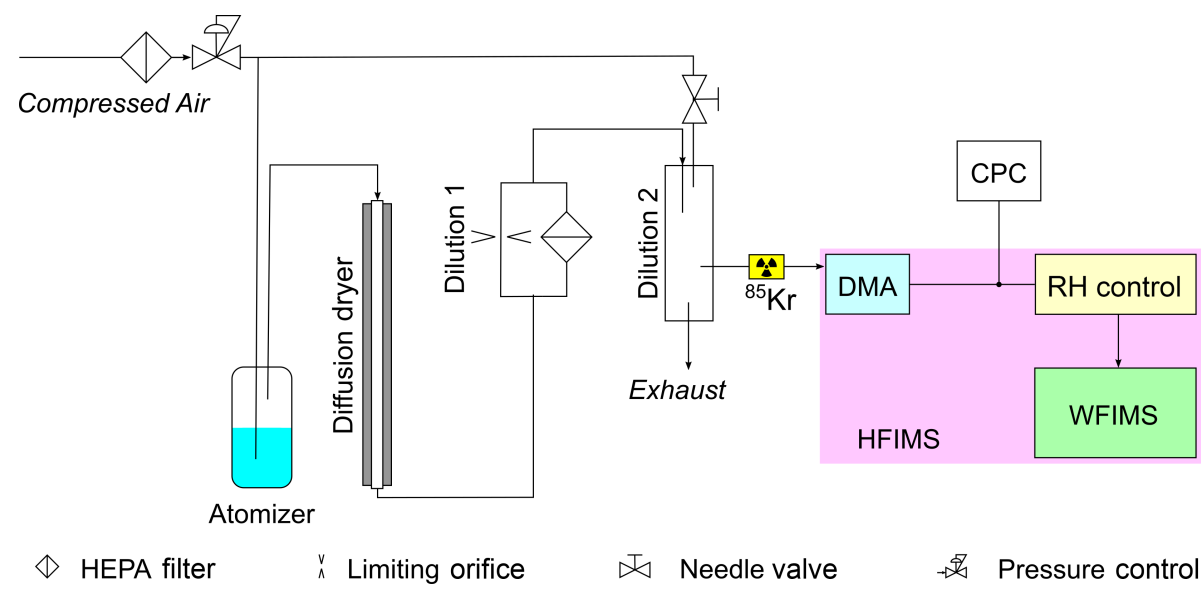

Figure 3. Experimental setup for laboratory characterization of the HFIMS.

stream of the HFIMS' DMA in parallel to the RH-controlWFIMS branch, and it provided the concentration of sizeselected dry particles. The WFIMS was operated at constant separating voltage $V$ of $1000 \mathrm{~V}$ corresponding to a growth factor window of 0.9 to 3.2. A detailed list of the HFIMS configuration parameters during the laboratory characterization can be found in the Supplement Sect. S2. Note that due to non-idealities of the electric field, instrument response mobilities $Z_{\mathrm{p}}^{*}$ were calculated using Eq. (1) with an effective voltage $V_{\text {eff }}$ instead of the applied voltage $V$ (Eq. 2). The $V_{\text {eff }}$ was derived following a calibration procedure detailed in the Supplement Sect. S3.

For the measurements of the deliquescence and hygroscopic growth of $\mathrm{NaCl}$ particles, we matched the relative humidity of aerosol and sheath flows $\left(\mathrm{RH}_{\mathrm{a}}=\mathrm{RH}_{\mathrm{sh}}\right)$. The measurement of efflorescence was carried out by keeping $\mathrm{RH}_{\mathrm{a}}$ at $85 \%$ while varying $\mathrm{RH}_{\mathrm{sh}}$ between 18.8 and $79.9 \%$.

The measurement speed of the HFIMS was evaluated by sampling ambient aerosols outside of our laboratory at Brookhaven National Laboratory (Upton, New York). Figure 4 shows the schematic of the experimental setup. We obtained ambient particle growth factors at $\mathrm{RH}_{\mathrm{a}}=\mathrm{RH}_{\mathrm{sh}}=$
$85 \%$ for various dry particle diameters including five diameters (i.e., 35, 50, 70, 110 and $165 \mathrm{~nm}$ ) used by EUSAAR (Duplissy et al., 2009). A detailed list of the HFIMS configuration parameters during ambient tests can be found in the Supplement Sect. S4. Ambient particles with dry diameter up to $110 \mathrm{~nm}$ were classified with a nano-column DMA (TSI Inc., model 3085); above $110 \mathrm{~nm}$ a long-column DMA (TSI Inc., model 3081) was used. Whereas different DMAs were used to classify particles with different diameters in these preliminary tests, future systems will consist of a single DMA. As a result, the time required to switch between nanoand long-column DMAs was not considered when evaluating the HFIMS' measurement speed. As the classified dry particle diameter varied, the WFIMS separating voltage $V$ and hence mobility diameter window were adapted accordingly, and the values are listed in the Supplement Sect. S4. 


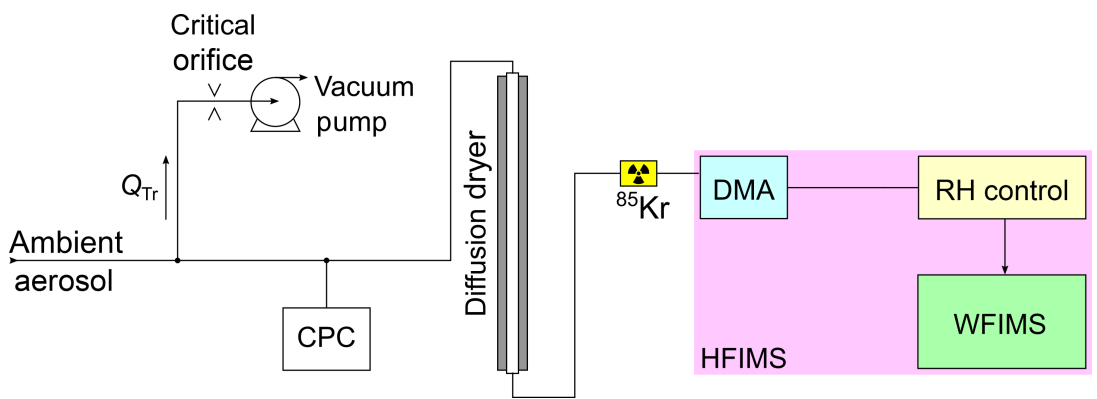

Figure 4. Experimental setup for measuring hygroscopic growth of ambient particles.

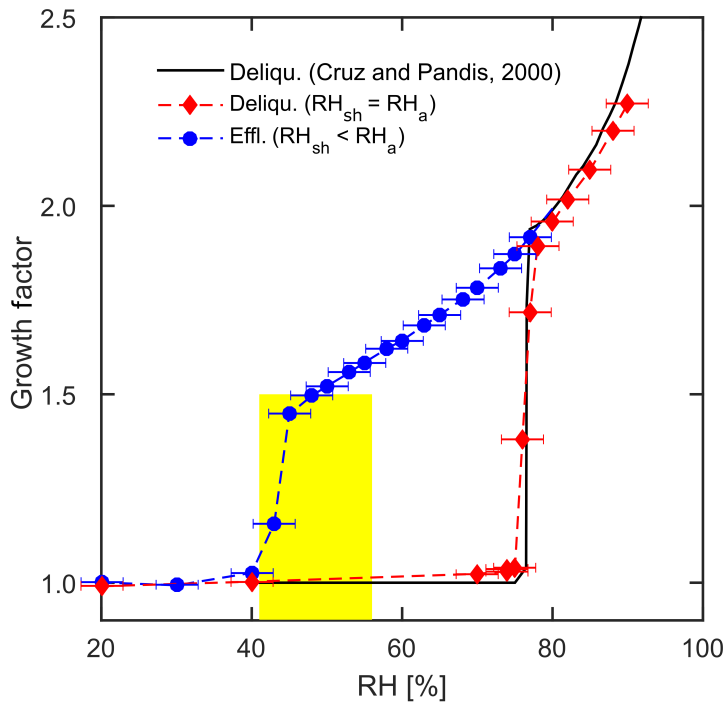

Figure 5. Mean growth factor of $\mathrm{NaCl}$ particles $\left(D_{\mathrm{p}, 0}=50 \mathrm{~nm}\right)$ measured by the HFIMS as a function of relative humidity $(\mathrm{RH})$ for both deliquescence (red diamonds) and efflorescence (blue circles) branches. Horizontal error bars indicate the RH sensor (Vaisala, model HMP60) accuracy of $\pm 3 \%$. Vertical error bars, which represent the standard error of the mean (SEM) growth factor, are covered by the data point symbols. The solid (black) line represents $\mathrm{NaCl}\left(D_{\mathrm{p}, 0}=100 \mathrm{~nm}\right)$ deliquescence curve reported by Cruz and Pandis (2000). The yellow area indicates the range of efflorescence transitions reported in the literature.

\section{Results and discussion}

\subsection{Laboratory evaluation with $\mathrm{NaCl}$ particles}

Growth factors of $50 \mathrm{~nm} \mathrm{NaCl}$ particles measured under both increasing (i.e., deliquescence branch, red diamonds) and decreasing (efflorescence branch, blue circles) RH conditions are shown in Fig. 5. Measurements of the deliquescence branch were carried out with matching aerosol and sheath $\mathrm{RH}$ (i.e., $\mathrm{RH}=\mathrm{RH}_{\mathrm{a}}=\mathrm{RH}_{\text {sh }}$ ). To account for the cubic shape of dry $\mathrm{NaCl}$ particles we used a shape correction factor of 1.08 (Zelenyuk et al., 2006). Hence, measured mo- bility equivalent diameters were decreased by about $4 \%$ to obtain volume equivalent diameters.

The $\mathrm{NaCl}$ deliquescence transition observed by the HFIMS is just over $76 \%$, which is in agreement with the theoretical value of $76.5 \%$ (Ming and Russell, 2001) and measurements by Hämeri et al. (2001) and Cruz and Pandis (2000) of 76 and $75.6 \%$, respectively. It should be mentioned that around the deliquescence transition two distinct size modes are observed (see Fig. 6). This suggests some heterogeneity in the RH of the aerosol sample (i.e., some particles experienced slightly higher RH than others), which is likely due to temperature variations among different parts of the system. Deliquescence transition data shown in Fig. 5 represent the number-weighted mean growth factor for the two modes. Improved RH and temperature control could minimize the RH heterogeneity and will be a topic of future study. Above the deliquescence transition, growth factors measured by the HFIMS are within $2 \%$ of theoretical values, suggesting the RH heterogeneity has negligible impact on measured particle growth factors above the deliquescence RH (e.g., at $85 \%$ ).

Figure 5 also shows the efflorescence curve (blue circles), that is the size change when the relative humidity environment decreases. Data were obtained by maintaining $\mathrm{RH}_{\mathrm{a}}$ constant at $85 \%$ while varying $\mathrm{RH}_{\text {sh }}$ between 18.8 and $79.9 \%$. Hence, the sheath flow was used to condition the sample RH - a feature made possible by the new offset electrode (see Sect. 2.2). As demonstrated in the Supplement Sect. S5 the RH of the mixed flow reaches the average value very quickly, such that the RH becomes uniform at the start of the electric field when the offset electrode is used. Humidified particle diameters $D_{\mathrm{p}}$ were measured at RH given by

$\mathrm{RH}=\left(Q_{\mathrm{a}} \cdot \mathrm{RH}_{\mathrm{a}}+Q_{\mathrm{sh}} \cdot \mathrm{RH}_{\mathrm{sh}}\right) /\left(Q_{\mathrm{a}}+Q_{\mathrm{sh}}\right)$.

It is common for salt aerosols to exhibit this type of hysteresis, with the droplet becoming supersaturated while gradually decreasing in size until finally recrystallizing at a much lower relative humidity. We observed recrystallization near $43 \% \mathrm{RH}$, which is close to the value of $44 \%$ reported by Biskos et al. (2006) and within the range of 41 to $56 \%$ (yellow area) reported in the literature. 
(a) $75 \% \quad 76 \% \quad 77 \% \quad 78 \%$

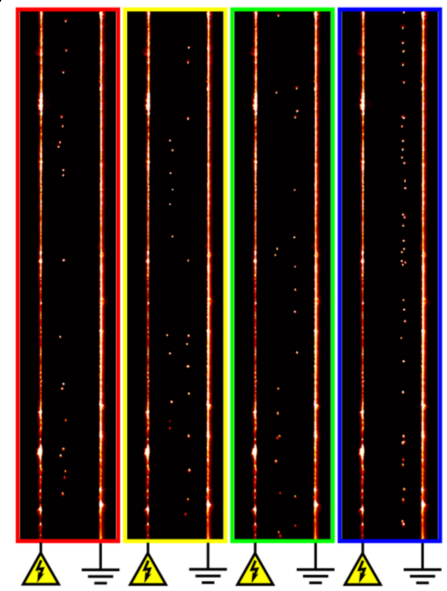

(b)

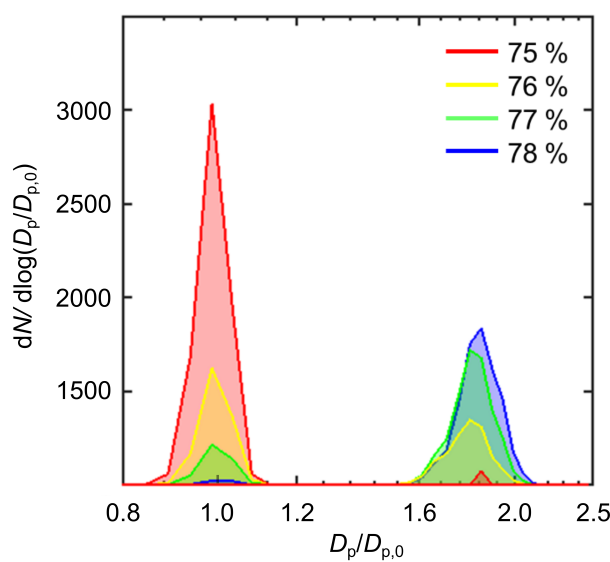

Figure 6. (a) Camera images showing particle positions and (b) growth factor distributions of $\mathrm{NaCl}$ particles $\left(D_{\mathrm{p}, 0}=50 \mathrm{~nm}\right) \mathrm{measured}$ around the deliquescence point. Red, yellow, green and blue distributions correspond to 75, 76, 77 and $78 \%$ RH, respectively.

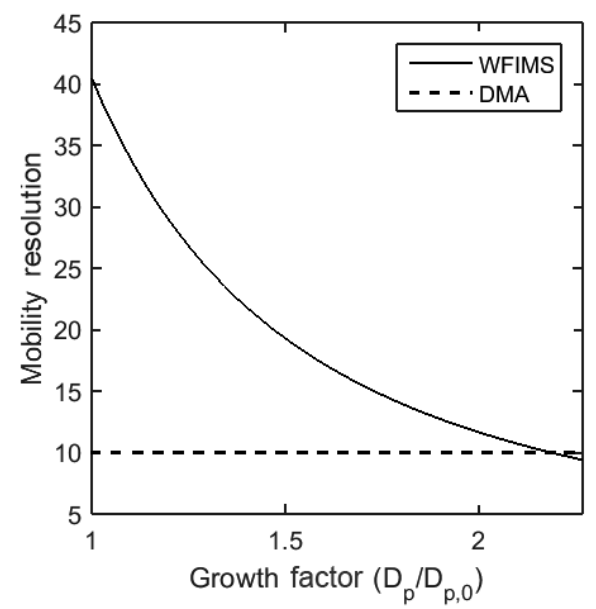

Figure 7. WFIMS mobility resolution (solid line) and typical DMA mobility resolution (dashed line) as a function of growth factor $\left(D_{\mathrm{p}} / D_{\mathrm{p}, 0}\right)$ for nondiffusing particles with $50 \mathrm{~nm}$ dry size.

Using the HFIMS operating conditions listed in the supplement (Sect. S2) we calculated the resolution of its sizing unit, i.e., the WFIMS, as a function of the hygroscopic growth factor for nondiffusing particles and compared it to the typical resolution of a DMA, i.e., 10. As shown in Fig. 7 the mobility resolution of the HFIMS is equal to, or exceeds that of, the HTDMA over the measured growth factor range, i.e., 1-2.27, shown in Fig. 5.

\subsection{Ambient particle hygroscopicity measurement}

Characterization of ambient aerosol hygroscopicity often requires measurements at multiple particle sizes within a reasonable time. This is often challenging for measurements using traditional TDMA systems, especially for the larger parti- cles which are low in number concentration and the smallest particles which have low charging efficiency.

Figure 8 shows results from ambient measurements with the HFIMS, where we evaluated the relative standard error of the mean growth factor (SEM of $\overline{\mathrm{GF}}$ ) as a function of particle counts $C$, and corresponding sample duration. Note that as the mean particle growth factor is given by the ratio of the wet to dry particle diameter, $\overline{D_{\mathrm{p}}}$ and $D_{\mathrm{p}, 0}$, respectively, the relative precision in measured $\overline{\mathrm{GF}}$ can be approximated by the relative precision in measured $\overline{D_{\mathrm{p}}}$ since

$$
\begin{aligned}
& \frac{\operatorname{SEM}(\overline{\mathrm{GF}})}{\overline{\mathrm{GF}}} \\
& =\frac{\sqrt{\left(\frac{\partial \overline{\mathrm{GF}}}{\partial \overline{D_{\mathrm{p}}}}\right)^{2} \cdot \operatorname{SEM}^{2}\left(\overline{D_{\mathrm{p}}}\right)+\left(\frac{\partial \overline{\mathrm{GF}}}{\partial D_{\mathrm{p}, 0}}\right)^{2} \cdot\left(\Delta D_{\mathrm{p}, 0}\right)^{2}}}{\overline{\mathrm{GF}}} \\
& \approx \frac{\operatorname{SEM}\left(\overline{D_{\mathrm{p}}}\right)}{\overline{D_{\mathrm{p}}}} .
\end{aligned}
$$

Total particle concentrations were relatively low, around $2200 \mathrm{~cm}^{-3}$, which is similar to what might be expected for continental background. The standard error of the mean for $\overline{D_{\mathrm{p}}}$ is estimated as

$\operatorname{SEM}\left(\overline{D_{\mathrm{p}}}\right)=\frac{\mathrm{SD}}{\sqrt{C}}$,

where $C$ is the number of particles counted and SD the sample standard deviation given by

$\mathrm{SD}=\sqrt{\frac{\sum_{i=1}^{C}\left(D_{\mathrm{p}, i}-\overline{D_{\mathrm{p}}}\right)^{2}}{C}}$,

with $D_{\mathrm{p}, i}$ being the diameter of the $i$ th particle measured. The relative SEM of $\overline{\mathrm{GF}}$ can be derived by combining Eqs. (5) 

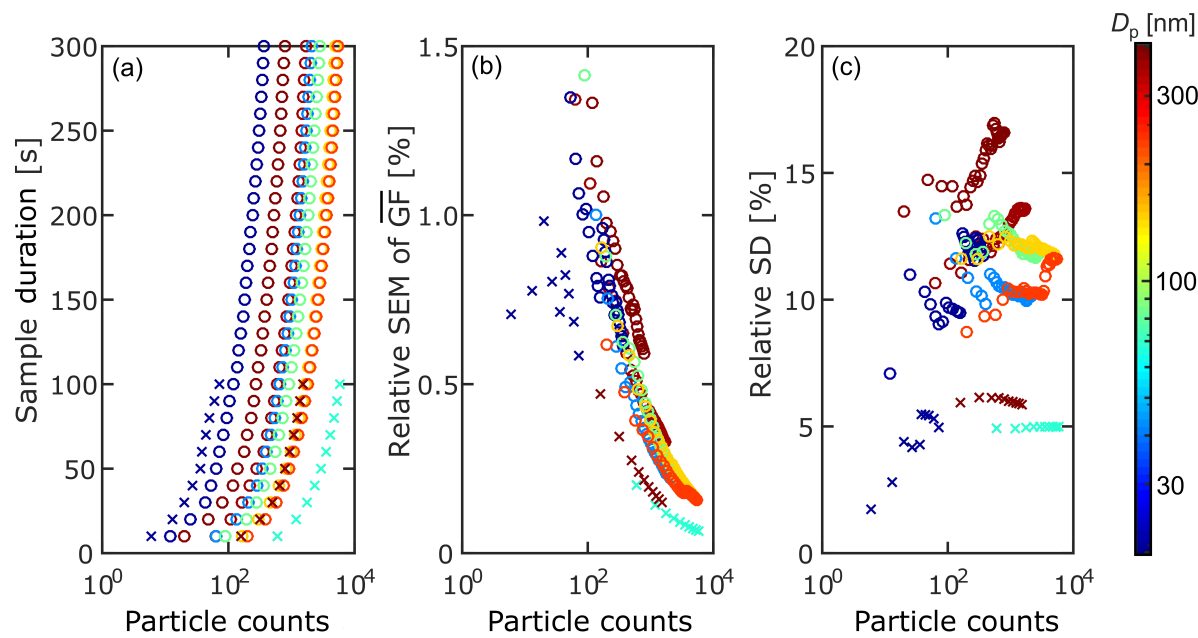

Figure 8. (a) Sample duration, (b) relative standard error (SEM) of the mean particle growth factor $\overline{\text { GF }}$ and (c) relative standard deviation (SD) of the sample particle size distribution as a function of total particle counts for the ambient aerosols sampled on 6 November (crosses) and 3 December (circles) 2015. Color coding represents mean particle wet sizes at $\mathrm{RH}=85 \%$.

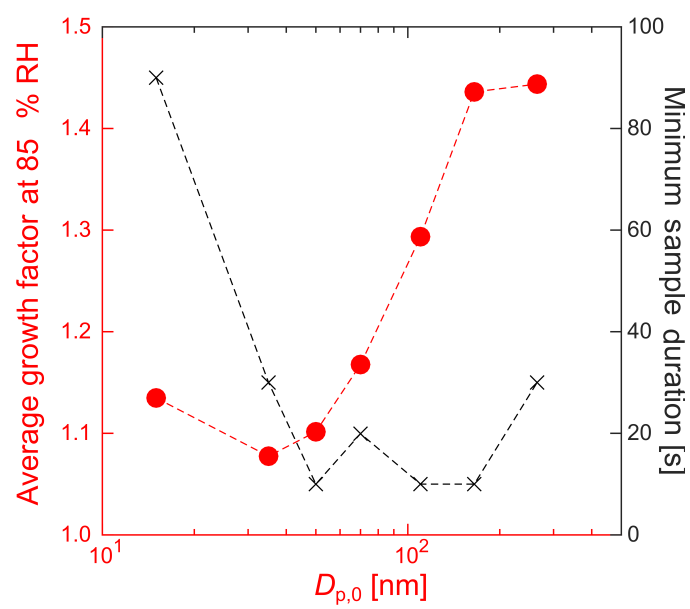

Figure 9. Size-dependent average growth factor at $\mathrm{RH}=85 \%$ (red circles) and corresponding minimum sample duration (black crosses) of ambient particles sampled on 3 December 2015.

and (6):

$\frac{\mathrm{SEM}(\overline{\mathrm{GF}})}{\overline{\mathrm{GF}}}=\frac{\mathrm{SD}}{\overline{D_{\mathrm{p}}} \sqrt{C}}$.

Note while the sample standard deviation SD, which is a measure of the dispersion of measured particle sizes from the sample mean diameter $\overline{D_{\mathrm{p}}}$, asymptotically reaches the population SD as $C$ increases (see Fig. 8c), SEM, which is a measure for the uncertainty of the sample mean growth factor around the population mean, approaches zero with increasing sample size (see Fig. 8b) - a behavior also known as law of large numbers. For narrow particle number size distributions $\left(\mathrm{SD}<0.2 \cdot D_{\mathrm{p}}\right)$ the number of particles required to reach better than $1 \%$ precision in growth factor is on the order of 100 . The required time to detect this many particles, from now on referred to as minimum sample duration, ranged from about $100 \mathrm{~s}$ at $15 \mathrm{~nm}$ to less than $30 \mathrm{~s}$ between 35 and $165 \mathrm{~nm}$.

Figure 9 shows the average growth factors of ambient aerosol (red circles) and corresponding minimum sample duration (black crosses) measured at a constant $\mathrm{RH}$ of $85 \%$ on 3 December 2015. Larger particles $\left(D_{\mathrm{p}, 0} \geq 110 \mathrm{~nm}\right)$ were observed to be more hygroscopic ( $\overline{\mathrm{GF}}>1.33)$. This indicates that larger particles originated from regional background aerosol, which had been processed during transport resulting in a higher soluble fraction (Swietlicki et al., 2008). Below $110 \mathrm{~nm}$, particles were found to be nearly hydrophobic $(\overline{\mathrm{GF}}=1.0-1.11)$. In this size range, particles were probably dominated by freshly emitted combustion particles containing soot and water-insoluble organic compounds (Weingartner et al., 1997) as aerosol was sampled near a parking lot.

In addition to the average growth factor, the GF distribution of the humidified aerosol, its width, and whether it is unimodal or bimodal are examined. Figure 10 compares size distributions of the humidified aerosol obtained by the HFIMS at five particle sizes recommended by the EUSAAR project for $20 \mathrm{~s}$ (black) and after $200 \mathrm{~s}$ (red) of sampling time. All data are for size-selected, initially dry ambient particles humidified to $85 \% \mathrm{RH}$. Note that the short counting times reproduce the final GF distribution nicely. Widths of the distributions are visually identical. Both short and long sample durations reveal a more hygroscopic mode appearing at $35 \mathrm{~nm}$, growing in prominence at $70 \mathrm{~nm}$ and becoming dominant above $110 \mathrm{~nm}$.

These analyses indicate that the hygroscopic growth factors at the five particle sizes could be captured by the HFIMS within 3 min, including a $15 \mathrm{~s}$ waiting time to ensure the sys- 

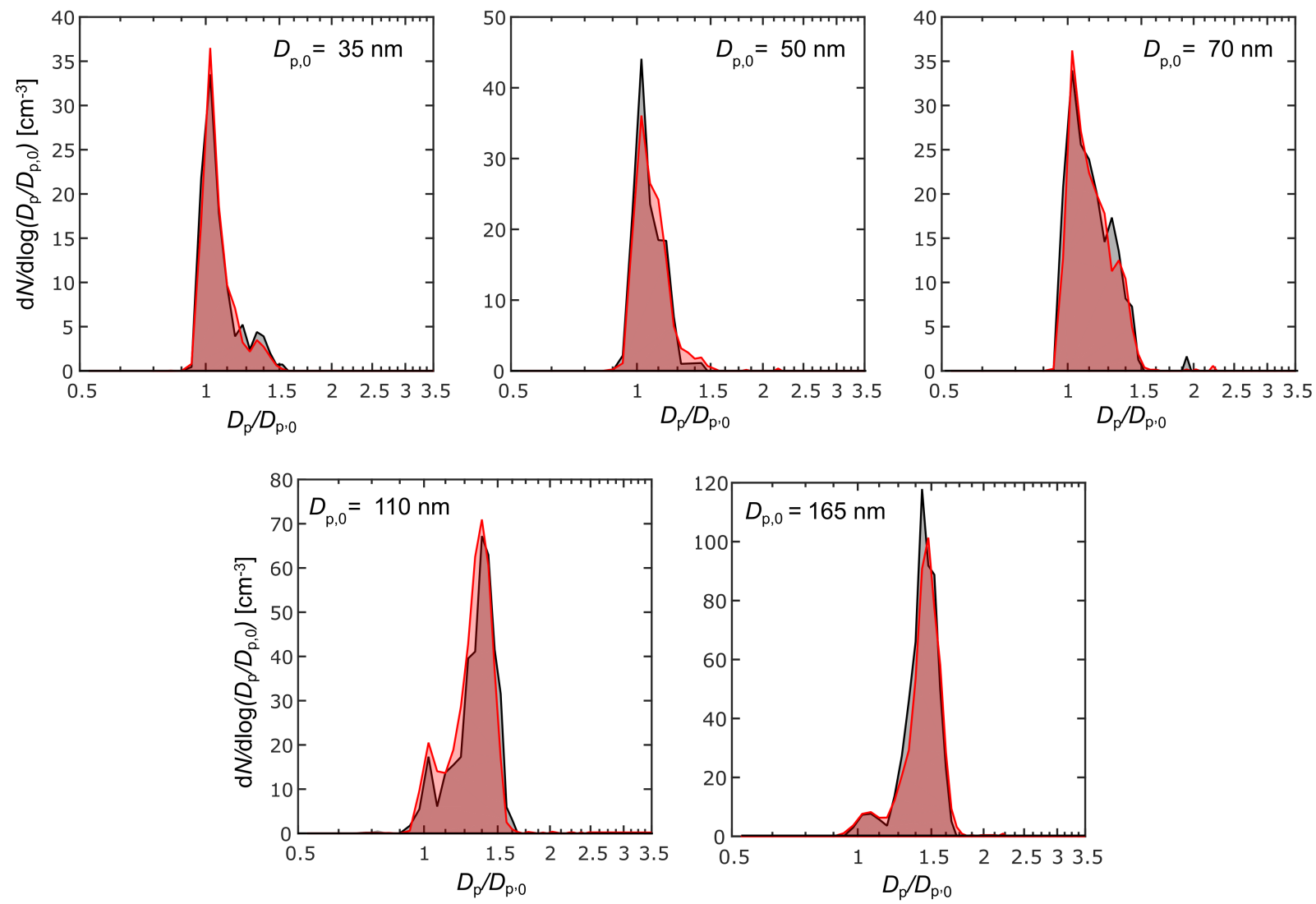

Figure 10. Comparison of GF distributions of size-selected ambient particles humidified to $85 \%$ for short (20 s, black) and long (200 s, red) sampling periods.

tem reaches steady state following the switching between different $D_{\mathrm{p}, 0}$. Similar measurements using conventional HTDMA systems often take about $30 \mathrm{~min}$ or more; therefore, the HFIMS represents an order of magnitude improvement in the measurement speed.

\section{Conclusions}

We present a humidity-controlled water-based fast integrated mobility spectrometer for rapid measurement of particle hygroscopicity.

The HFIMS consists of a DMA, an RH control unit and a water-based fast integrated mobility spectrometer (Pinterich et al., 2017). The WFIMS combines a single highvoltage FIMS (Kulkarni and Wang, 2006a) with the laminar flow water condensation methodologies developed by Hering and coworkers (e.g., Hering and Stolzenburg, 2005). By detecting particles of different sizes simultaneously, the WFIMS provides rapid-mobility-based measurements of particle size distributions over a factor of 3 or more in particle diameter, which is sufficient to cover the entire range of growth factor for ambient aerosol particles. Thus, with the combination of a DMA, relative humidity control and WFIMS, the HFIMS can capture the complete growth factor distribution of size selected particles with much improved speed.

Laboratory experiments with $\mathrm{NaCl}$ particles showed that the HFIMS can reproduce theoretical growth factors within $2 \%$. The deliquescence transition was observed just over $76 \%$, which is in excellent agreement with the theoretical value of $76.5 \%$ (Ming and Russell, 2001). The measured efflorescence relative humidity $(43 \%)$ was found to lie within the range of 41 to $56 \%$ reported in the literature.

The hygroscopicity of ambient aerosols was characterized by keeping the sample and sheath RH at $85 \%$ and varying the dry particle size. We found that growth factors of ambient particles ranging from 35 to $165 \mathrm{~nm}$ could be measured within less than $3 \mathrm{~min}$, providing approximately a factor of 10 increase in the time resolution. The system will greatly improve our capability to study particle hygroscopic growth, especially for rapidly evolving aerosol populations. 
Data availability. Data sets used in this article will be provided by the corresponding author (Jian Wang, jian@bnl.gov) upon request.

\section{The Supplement related to this article is available online at https://doi.org/10.5194/amt-10-4915-2017-supplement.}

Competing interests. The authors declare that they have no conflict of interest.

Acknowledgements. We thank Andrew McMahon for his help with the development of the offset high-voltage electrode. This work was supported by the US Department of Energy, Office of Science, Small Business Technology Grants DE-SC0006312 and DE-SC0013103.

\section{Edited by: Mingjin Tang}

Reviewed by: two anonymous referees

\section{References}

Albrecht, B. A.: Aerosols, cloud microphysics, and fractional cloudiness, Science, 245, 1227-1230, 1989.

Biskos, G., Malinowski, A., Russell, L. M., Buseck, P. R., and Martin, S. T.: Nanosize effect on the deliquescence and the efflorescence of sodium chloride particles, Aerosol Sci. Tech., 40, 97106, 2006.

Cerully, K. M., Raatikainen, T., Lance, S., Tkacik, D., Tiitta, P., Petäjä, T., Ehn, M., Kulmala, M., Worsnop, D. R., Laaksonen, A., Smith, J. N., and Nenes, A.: Aerosol hygroscopicity and CCN activation kinetics in a boreal forest environment during the 2007 EUCAARI campaign, Atmos. Chem. Phys., 11, 12369-12386, https://doi.org/10.5194/acp-11-12369-2011, 2011.

Chen, R., Hu, B., Liu, Y., Xu, J., Yang, G., Xu, D., and Chen, C.: Beyond $\mathrm{PM}_{2.5}$ ?: the role of ultrafine particles on adverse health effects of air pollution, BBA-Gen. Subjects, 1860, 2844-2855, 2016.

Cruz, C. N. and Pandis, S. N.: Deliquescence and hygroscopic growth of mixed inorganic-organic atmospheric aerosol, Environ. Sci. Technol., 34, 4313-4319, 2000.

Duplissy, J., Gysel, M., Sjogren, S., Meyer, N., Good, N., Kammermann, L., Michaud, V., Weigel, R., Martins dos Santos, S., Gruening, C., Villani, P., Laj, P., Sellegri, K., Metzger, A., McFiggans, G. B., Wehrle, G., Richter, R., Dommen, J., Ristovski, Z., Baltensperger, U., and Weingartner, E.: Intercomparison study of six HTDMAs: results and recommendations, Atmos. Meas. Tech., 2, 363-378, https://doi.org/10.5194/amt-2363-2009, 2009.

Hämeri, K., Laaksonen, A., Väkevä, M., and Suni, T.: Hygroscopic growth of ultrafine sodium chloride particles, J. Geophys. Res., 106, 20749-20757, 2001.

Hering, S. V. and Stolzenburg, M. R.: A method for particle size amplification by water condensation in a laminar thermally diffusive flow, Aerosol Sci. Tech., 39, 428-436, 2005.
Hering, S. V., Spielman, S. R., and Lewis, G. S.: Moderated water based condensational particle growth in a laminar flow, Aerosol Sci. Tech., 48, 401-408, 2014.

IPCC: Climate Change 2013: The physical science basis: contribution of working group $i$ to the fourth assessment report of the intergovernmental panel on climate change, Cambridge University Press, Cambridge, United Kingdom and New York, NY, USA, 2013.

Kulkarni, P. and Wang, J.: New fast integrated mobility spectrometer for real-time measurement of aerosol size distribution - I: concept and theory, J. Aerosol Sci., 37, 1303-1325, 2006 a.

Kulkarni, P. and Wang, J.: New fast integrated mobility spectrometer for real-time measurement of aerosol size distribution: II. design, calibration, and performance characterization, J. Aerosol Sci., 37, 1326-1339, 2006b.

Leinert, S. and Wiedensohler, A.: A DMA and APS based technique for measuring aerodynamic hygroscopic growth factors of micrometer-size aerosol particles, J. Aerosol Sci., 39, 393-402, 2008.

Liu, X. and Wang, J.: How important is organic aerosol hygroscopicity to aerosol indirect forcing?, Environ. Res. Lett., 5, 44010, https://doi.org/10.1088/1748-9326/5/4/044010, 2010.

Lopez-Yglesias, X. F., Yeung, M. C., Dey, S. E., Brechtel, F. J., and Chan, C. K.: Performance evaluation of the Brechtel Mfg. Humidified Tandem Differential Mobility Analyzer (BMI HTDMA) for studying hygroscopic properties of aerosol particles, Aerosol Sci. Tech., 48, 9969-980, 2014.

Mei, F., Setyan, A., Zhang, Q., and Wang, J.: CCN activity of organic aerosols observed downwind of urban emissions during CARES, Atmos. Chem. Phys., 13, 12155-12169, https://doi.org/10.5194/acp-13-12155-2013, 2013.

Ming, Y. and Russell, L. M.: Predicted hygroscopic growth of sea salt aerosol, J. Geophys. Res.-Atmos., 106, 28259-28274, 2001.

Olfert, J. S., Kulkarni, P., and Wang, J.: Measuring aerosol size distributions with the fast integrated mobility spectrometer, J. Aerosol Sci., 39, 940-956, 2008.

Pinterich, T., Spielman, S. R., Hering, S. V., and Wang, J.: A water-based fast integrated mobility spectrometer with enhanced dynamic size range, Aerosol Sci. Tech., 51, 1212-1222, https://doi.org/10.1080/02786826.2017.1338664, 2017.

Sorooshian, A., Hersey, S., Brechtel, F. J., Corless, A., Flagen, R. C., and Seinfeld, J. H.: Rapid, size-resolved aerosol hygroscopic growth measurements: Differential Aerosol Sizing and Hygroscopicity Spectrometer Probe (DASH-SP), Aerosol Sci. Tech., 42, 445-464, 2008.

Spielman, S. R., Hering, S. V., Kuang, C., and Wang, J.: Preliminary investigation of a water-based method for fast integrating mobility spectrometry, Aerosol Sci. Tech., https://doi.org/10.1080/02786826.2017.1338338, 51, 12231230, 2017.

Stolzenburg, M. R., Kreisberg, N. M., and Hering, S. V.: Atmospheric size distributions measured by differential mobility optical particle size spectrometry, Aerosol Sci. Tech., 29, 402-418, 1998.

Surratt, J. D., Chan, A. W. H., Eddingsaas, N. C., Chan, M. N., Loza, C. L., Kwan, A. J., Hersey, S. P., Flagan, R. C., Wennberg, P. O., and Seinfeld, J. H.: Reactive intermediates revealed in secondary organic aerosol formation from isoprene, $\mathrm{P}$. Natl. Acad. Sci. USA, 107, 6640-6645, 2010. 
Swietlicki, E., Hansson, H.-C., Hämeri, K., Svenningsson, B., Massling, A., McFiggans, G., McMurry, P. H., Petäjä, T., Tunved, P., Gysel, M., Topping, D., Weingartner, E., Baltensperger, U., Rissler, J., Wiedensohler, A., and Kulmala, M.: Hygroscopic properties of submicrometer atmospheric aerosol particles measured with H-TDMA instruments in various environments - a review, Tellus B, 60, 432-469, 2008.

Twomey, S.: The influence of pollution on the shortwave albedo of clouds, J. Atmos. Sci., 34, 1149-1152, 1977.

Weingartner, E., Baltensperger, U., and Burtscher, H.: Growth and structural changes of combustion aerosols at high relative humidity, J. Aerosol Sci., 26, S667-S668, 1995.
Weingartner, E., Burtscher, H., and Baltensperger, U.: Hygroscopic properties of carbon and diesel soot particles, Atmos. Environ., 31, 2311-2327, 1997.

Zelenyuk, A., Cai, Y., and Imre, D.: From agglomerates of spheres to irregularly shaped particles: determination of dynamic shape factors from measurements of mobility and vacuum aerodynamic diameters, Aerosol Sci. Tech., 40, 197-217, 2006. 